\title{
Uterine Rupture in West African Dwarf Doe at Parturition
}

\author{
Wachida Ndumari*, Kisani Aboh, Terfa Nev and Iorhemba Utim Ate \\ Department of Veterinary Surgery and Theriogenology, University of Agriculture, Makurdi Benue State, Nigeria
}

Submission: October 26, 2017; Published: December 13, 2017

*Corresponding author: Wachida Ndumari, Department of Veterinary Surgery and Theriogenology, College of Veterinary Medicine, University of Agriculture P.M.B 2373, Makurdi, Benue State, Nigeria, Tel: +2348036377320; Email: ndumariwachida@gmail.com

\begin{abstract}
A rupture of the uterus was observed in 21/2 years old pleuripara West African Dwarf Does (WAD) weighing $22 \mathrm{~kg}$ which kidded a life kid normally over night, but was observed with ventral distended abdomen the previous morning. Obstetrical examination revealed a ruptured uterus with another foetus in the abdominal wall. Ceasarean section delivery was indicated, the foetus was found dead in the abdominal wall with uterine content. The uterine tear was beyond repair the doe underwent ovariohysterectomy and recovered without complication.
\end{abstract}

Keywords: Ruptured uterus; West African dwarf doe; Ceasarean section; Ovariohysterectomy; Foetus

\section{Introduction}

Rupture of the gravid uterus is a rare finding in does particularly West African Dwarf does; there is therefore very scanty information about uterine rupture in ruminant generally. The only available documented information in ruminant is the report of uterine rupture with live twins in a Holstein Frisian cow as a result of incomplete dilation of cervix in Iraqi by Azawi et al. [1]. Stone et al. [2] stated that uterine rupture in a pregnant bitch can occur following uterine torsion or trauma. The prevalence of uterine rupture in bitches is not known. Stolla et al. [3] carried out a 14-year investigation at a university clinic in Germany, and did not observe uterine rupture in any of the 337 bitches with dystocia examined by them. Likewise Darvelid \& Linde-Forsberg [4] failed to detect periparturient uterine rupture in 182 bitches with dystocia. However, Hajurka et al. [5] reported a case of uterine rupture in a bitch pregnant with a single puppy and evisceration of the puppy's intestine through the rupture. [12] reported a case of uterine rupture in a cat which was hit by a car.

A study was conducted by Ofir et al. [6] on Israeli women and uterine rupture accounted for $0.035 \%$ of 117685 childbirths. A literary review by Chauhan et al. [7] in the period between 19892001, involving women after preceding caesarian deliveries, showed that the attempt at vaginal parturition during the subsequent pregnancy resulted in uterine rupture in 6.2 per 1000 deliveries. Ofir et al. [6] listed the previous caesarean section, malpresentation and dystocia during the second stage of labour as the principal causes of uterine rupture in women, although in the subsequent study these authors [8] noted no significant differences between the rupture of a scarred and nonscarred uterus.

\section{Case History}

A 2 1/2 years old pleuripara West African Dwarf (WAD) doe weighing $22 \mathrm{~kg}$ was presented at the large animal Clinic floor of the Veterinary Teaching Hospital, University of Agriculture Makurdi Benue State, Nigeria with the chief complaint that the doe kidded a life female kid weighing $600 \mathrm{~g}$ normally overnight, by day break the owner observed the doe with hanging placenta on the vulva and the abdominal wall distended ventrally.

On physical examination, the doe was alert, the colour of the mucous membranes was pink, its temperature was $39.7^{\circ} \mathrm{C}$, there was placenta hanging on the vulva, ventrally distended abdomen and slight vaginal discharge with a healthy kid (Figure 1).

Obstetrical examination was performed and foetus was found in the abdominal wall. The treatment recommended was to perform laparotomy and repair the tear in the uterus. Haematological examination revealed haemoglobin (g/ dl) 9.4, hematocrit (PCV) (L/L) 29.0, RBC (x10²/l) 12.9, MCV(fL) 20.5, MCH(PG) 5.5, MCHC (g/L) 322, RDW (\%) 21.4, thrombocytes (x109L) 593, WBC (X109/L) 15.0, neutrophiles $44 \%$, granulocytes $\left(\mathrm{x} 10^{9} / \mathrm{L}\right)$ 9.3, lymphocytes (x10 $\left./ \mathrm{L}\right)$ 5.1, eosinophiles ( $\left.\mathrm{x} 10^{9} / \mathrm{L}\right) 0.5$, basophiles $0 \%$ all falls within the low normal. 


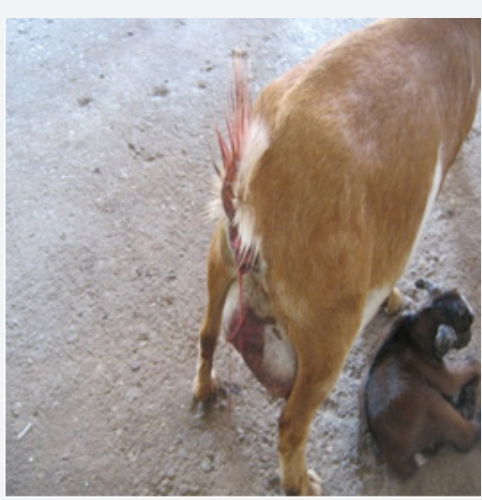

Figure 1: Doe \& kid at presentation.

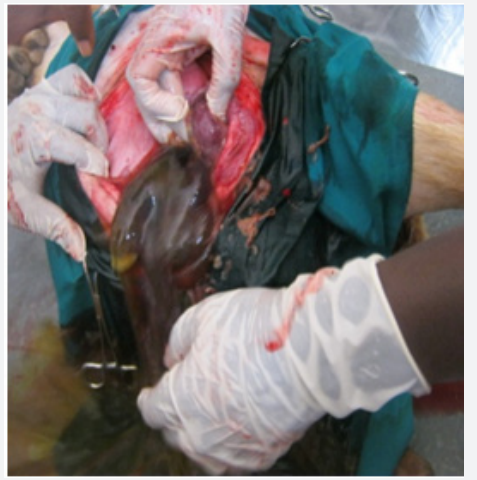

Figure 2: Foetus in the abdomen.

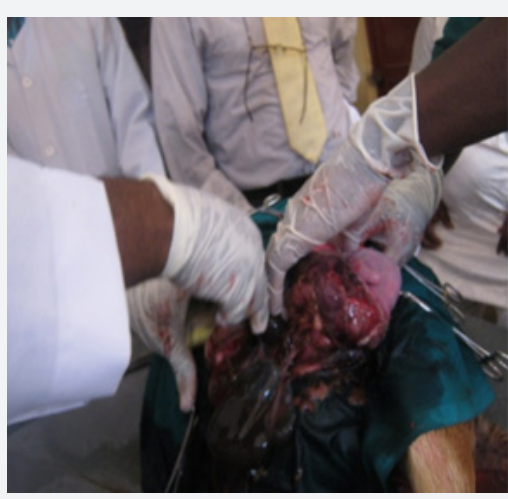

Figure 3: Ruptured uterus.

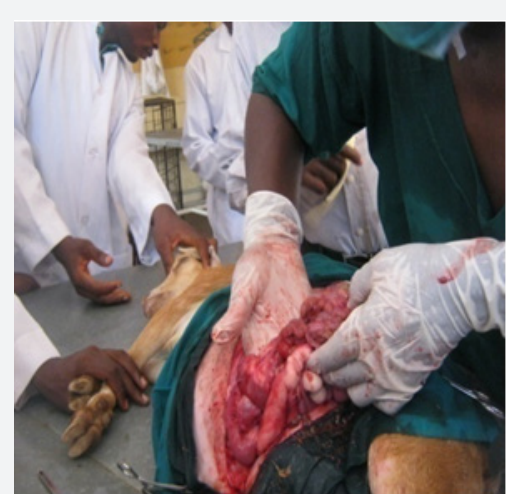

Figure 4: Ovariohysterectomy.
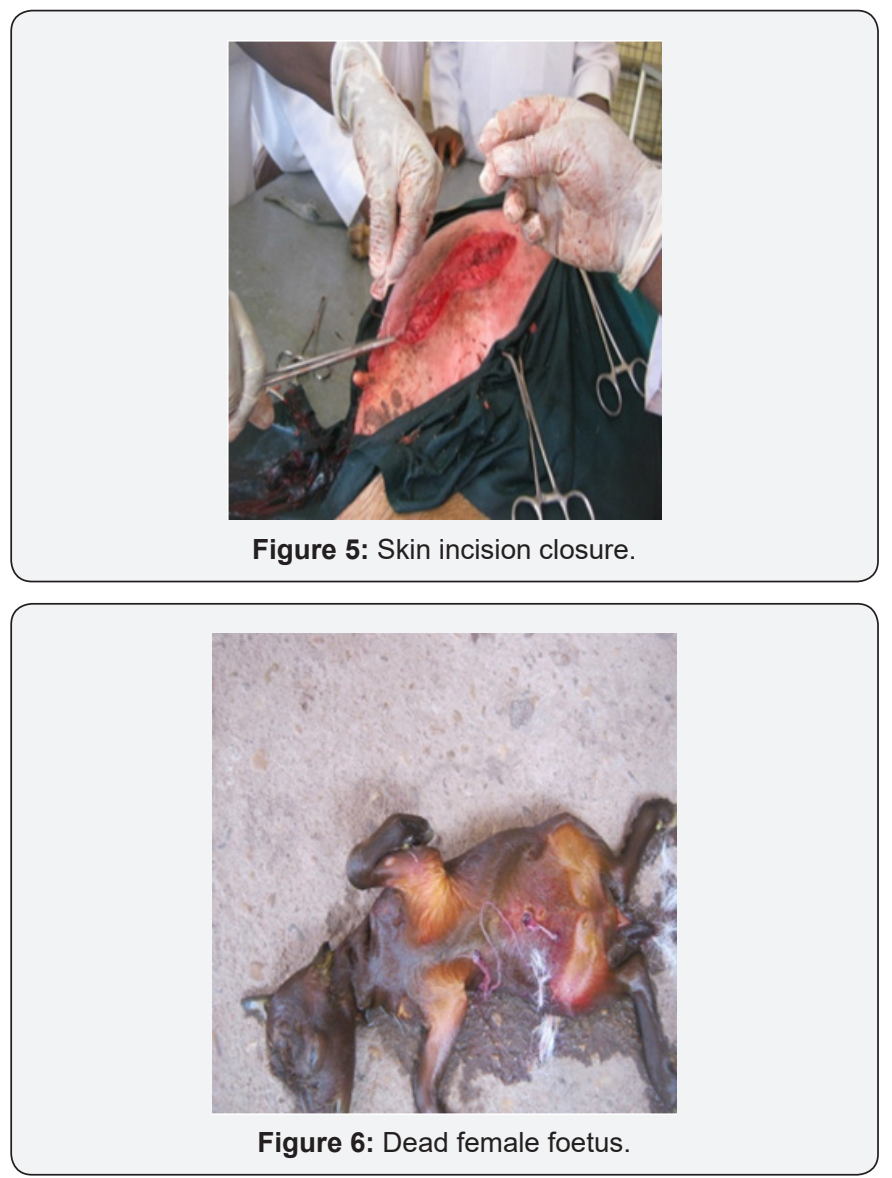

Laparotomy was performed using a standard left paralumber fossa approach on the doe after preparing the site aseptically. Inverted para-vetebral nerve block was performed using $10 \mathrm{mls}$ of $2 \%$ lidocaine hydrochloride. Dorso-ventral skin incision was made and the external, internal oblique abdominis muscles were incised to expose the peritoneum. Inspection of the abdomen showed the presence of a foetus which was 'free' and the uterine content in abdominal cavity Figure 2-5. The foetus was female weighing $900 \mathrm{~g}$ which was however, dead Figure 6. The tear on the uterus was beyond repair ovariohysterectomy was performed using standard approach Figure 4. The dorso-ventral skin incision was closed routinely Figure 5.

\section{Post- Operative Care}

Pentazocine $3 \mathrm{mg} / \mathrm{kg}$ was administered intramuscularly for 3 days as analgesic, dehydrostrptomycin and procaine penicillin $\mathrm{G}$ were administered intramuscularly at $5 \mathrm{mg} / \mathrm{kg}$ and $20,000 \mathrm{IU} /$ $\mathrm{kg}$ respectively for 7 days, the surgical site was dressed every other days and the stitches removed on day 12. The doe was monitored for four weeks after surgery and was discharged from the Hospital after full recovering.

\section{Discussion}

Periparturient uterine rupture often results from external trauma [9]. Rupture during the kidding is most likely to occur in cases which the uterine wall is compromised by the presence 
of infection, a dead foetus, uterine torsion, or careless obstetrics procedures. It can also be caused by excessively large doses of oxytocin [10]. In our case, the uterine rupture occurred during spontaneous delivery of an oversized foetus, which is in agreement with Hajurka et al. [5] who reported uterine rupture that occurred during spontaneous delivery of an oversized foetus in ventral position in a bitch. The fetal death in this case must have occurred after the rupture of the uterus due to foetumaternal disconnection and lost of uterine environment. Johnston et al. [11] warned that ecbolic drugs should not be used if obstructive dystocia is present because uterine rupture may occur. In our case, although no ecbolic were used, the uterine rupture resulted most probably from extensive pushing by the doe which might not have been observed by the owner since the incidence occurred at night. There was no other sign to suggest uterine rupture apart from the distended abdomen, our report has concurred with the report of [12], Yates \& McCoubrey [13] that uterine rupture in the cat is generally asymptomatic, with only abdominal distension occurring.

Uterine rupture is a rare finding in WAD does, this is the first case recorded in the Veterinary Teaching Hospital, University of Agriculture Makurdi, Benue State Nigeria since its establishment about 13 years ago. Also a reviewed of dystocia cases in does at the same Hospital was conducted between 2011-2016, out of 18 dystocia cases handled during this period none was associated with uterine rupture. Our report has agreed with the finding of [12] who reported uterine rupture as an unusual finding in cat. Also Stolla et al. [3] carried out a 14-year investigation at a university clinic in Germany, and did not observe uterine rupture in any of the 337 bitches with dystocia examined by them. Likewise Darvelid \& Linde-Forsberg [4] failed to detect periparturient uterine rupture in 182 bitches with dystocia.

\section{References}

1. Azawi IO, Ali JA, Naoman TU (2012) Uterine rupture with alive twins in a Holstein Frisian cow. Iraqi Journal of Veterinary Science 26(1): 27-28.
2. Stone EA, Cantrell CG, Charp NJH (1993) Reproductive system. In: Slatter D (Ed.), The Textbook of Small Animal Surgery ( $2^{\text {nd }}$ edn), WB Saunders Company, Philadelphia, USA, pp. 1293-1308.

3. Stolla R, Dusi-Farber B, Stengel B, Schmid G, Braun J (1999) Dystocia in the bitch: a retrospective study. Wiener Tierarztliche Monatsschrift 86: $145-149$.

4. Darvelid AW, Linde-Forsberg C (1994) Dystocia in the bitch: A retrospective study of 182 cases. Journal of Small Animal Practice 35(8): 402-407.

5. Hajurka J, Macak, V, Hura, V, Stavova L, Hajurka R (2005) Spontaneouse rupture of uterus in the bitch at parturition with evisceration of puppy intestine. J Vet Med Czech 50(2): 85-88.

6. Ofir K, Sheiner E, Levy A, Katz M, Mazor M (2003) Uterine rupture: Risk factors and pregnancy outcome. Am J Obstet Gynecol 189(4): 10421046.

7. Chauhan SP, Martin JN, Henrichs CE, Morrison JC, Magann EF (2003) Maternal and perinatal complications with uterine rupture in 142075 patients who attempted vaginal birth after cesarean delivery: A review of the literature. Am J Obstet Gynecol 189(2): 408-417.

8. Ofir K, Sheiner E, Levy A, Katz M, Mazor M (2004) Uterine rupture: differences between a scarred and an unscarred uterus. American Journal of Obstetrics and Gynecology 191(2): 425-429.

9. Webbs AI (1992) Venteral hernia and rupture of uterus in a cat. Aust Vet J 48(4): 212-214.

10. Jackson PGG (2004) Postparturient problems in the dog and cat. In: Jackson PGG (Ed.), Handbook of Veterinary Obstetrics. ( $2^{\text {nd }}$ edn), WB Saunders Company, Philadelphia, USA, pp. 233-237.

11. Johnston SD, Root Kustritz MV, Olson PNS (2001) Canine parturitionEutocia and Dystocia. In: Johnston SD, Root Kustritz MV and Olson PNS (Eds.), Canine and Feline Theriogenology $\left(1^{\text {st }} e d n\right)$, WB Saunders Company, Philadelphia, USA, p. 785.

12. Lucas X, Agut A, Ramis G, Belda E, Solar M (2013) Uterine rupture in a cat. Veterinary record 152, 301-302.

13. Yates D, McCourry G (1997) Abdominal distention in a cat. Veterinary record 141: 27

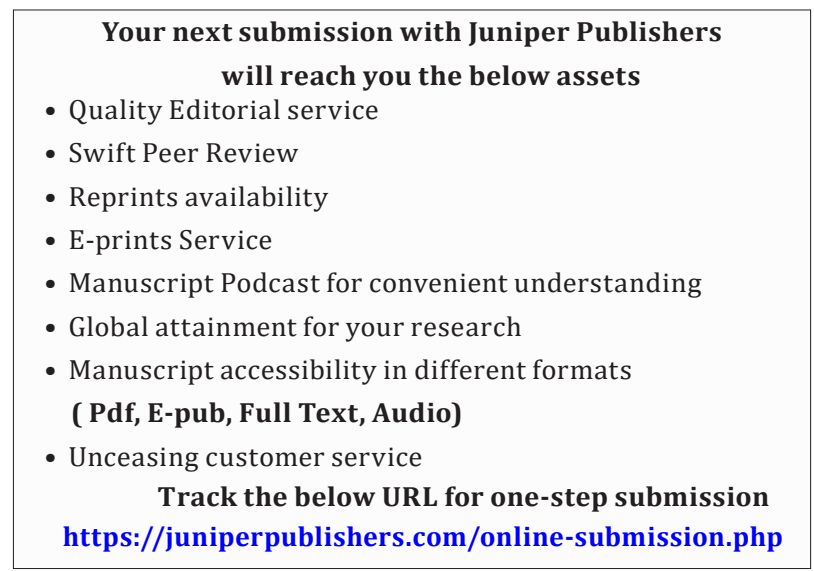

